\title{
EL FONDO MEDIEVAL DEL ARCHIVO MUNICIPAL DE MULA: PASADO Y PRESENTE. CATÁLOGO DE LOS PERGAMINOS MEDIEVALES.
}

\author{
Antonio Hernández Andújar ${ }^{l}$
}

\section{RESUMEN}

De toda la documentación medieval, en pergamino, actualmente conservada en el archivo municipal de Mula (Murcia), se hace catálogo-inventario desde la óptica diplomática, paleográfica, sigilográfica y codicológica, objeto del presente trabajo. Además, se hace una relación de la documentación que estuvo depositada en dicho archivo y la que actualmente hay en él.

Palabras clave: Mula, archivo, documentación, sigilografía, diplomática, paleografía.

\begin{abstract}
Of the whole medieval documentation, in parchment, at the moment conserved in the municipal archive of Mula (Murcia), it's made catalogue-inventory from the diplomatic, palaeographic, sigilographic and codicologic point of view, actual issue of this paper. Furthermore, it is made a list of the documentation that was deposited in the previously mentioned archive and the one currently available in it.
\end{abstract}

Key words: Mula, archive, documentation, sigilography, diplomatic, palaeography.

El Archivo Municipal de Mula está ubicado, junto a la biblioteca municipal, en el lugar donde estuvo desde el siglo XVI el antiguo Hospital de la Concepción, hoy un edificio restaurado del siglo XVIII. Este depósito tiene un innegable valor documental para conocer el devenir histórico de Mula y pueblos vecinos. La documentación que constituye el fondo municipal está inventariada, pero está aún por hacer una catalogación profunda del mismo.

1 Área de Ciencias y Técnicas Historiográficas. Dpto. Prehistoria, Arqueología, Historia Antigua, Historia Medieval y CCTTHH. Universidad de Murcia. Email: apoloandujar@hotmail.com. 
Es a través de los inventarios y de las noticias dadas por eruditos e investigadores, como se puede esbozar una relación detallada de la documentación que tuvo, y hoy día tiene, el Archivo Municipal. Dada la importancia que creo tiene, por su antigüedad, el fondo medieval, voy a circunscribirme a este periodo cronológico, analizando la documentación en pergamino existente en la actualidad; al tiempo que haré referencia a los documentos escriturados en papel así como a la documentación perdida.

En el Archivo Municipal se conservan varios inventarios realizados en época moderna ${ }^{2}$. En ellos se constata la documentación expedida y recibida por el concejo de la villa durante los siglos XVI y XVII, además de alguna documentación bajomedieval.

El inventario más antiguo data del 5 de Julio de 1621, con el título de Ynbentario de prouisiones del archiuo de Mula, y fue mandado a hacer por el capitán don Fernando de Párraga Yánez, alcalde ordinario, con asistencia de Diego Martínez de Exea, regidor, y de Garçi de Robles, escribano, siendo testigos Francisco Botía y Juan Sebastián de Graua ${ }^{3}$ y en presencia del notario Joan Beltrán. En dicho inventario se recogen algunos documentos medievales: "un padrón del año de mile y quatroçientos y quarenta y seis de hidalgos y pecheros”, un "padrón delos Juezes del año quatroçientos y nouenta y çinco", "un padrón de hijosdalgo y pecheros de mill quatroçientos y siete en doçe hojas" y "otro padrón de lo mismo (de hidalgos y pecheros) que el de arroba (sic) del año de mill y quatroçientos y treinta y ocho en çinco fojas de pliego entero doblado a la larga" ${ }^{5}$.

Otro inventario es el realizado en 1644, con el título de "Ynbentario de los papeles del archivo de la villa de Mula que se hiço año de 1644", del que se desconoce su autor, y en el que aparecen reseñados 443 documentos, de los cuales, del 383 al 411, corresponden a los privilegios y mercedes que otorgaron a Mula los reyes bajomedievales ${ }^{6}$. Tal relación es muy escueta, lo que dificulta la identificación de los documentos, al no poder, la mayoría, relacionarse con seguridad a un rey o, porque no aparece la fecha de emisión de documento. La serie de documentos es la siguiente:

383- Preuilejio del Portazgo; 384- Preuilexio que goçe esta villa del fuero de Cordoua y franqueça del Portazgo y peage; 385- Preuilexio de la grana de Cagitan y confirmaçion general de los preuilegios desta villa; 386- Preuilegio para que los vezinos desta villa no paguen derechos de almojarifazgo en Murçia;387Confirmaçion general de los preuilejios dado por el rey don enrrique cuarto; 388Preuilexio para que el conçejo pudiera escusar ochenta vezinos de la moneda forera; 389- Preuilegio dela confirmazion de los que confirmo el rey don Fernando Terçero ${ }^{7}$; 390- Confirmaçion general de los preuilejios por el rey don Pedro; 391- Preuilejio de la franqueza de Murçia y que nadie coja grana ni pazca ni corte madera contra la boluntad del conçejo; 392- Moxonera entre Mula y Zeegin de conformidad de anuas villas año de 1462; 393-Confirmaçion de los preuilexios; 394- Preuilejio del Infante

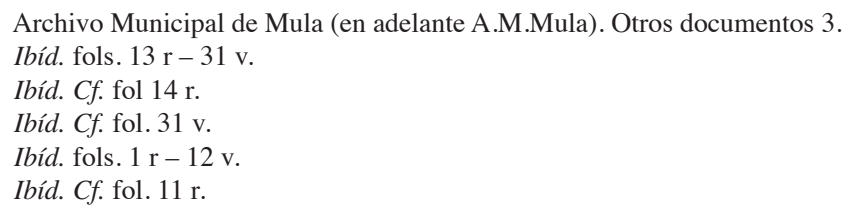


don Alfonso para que goçe esta villa el fuero de Cordoua; 395-Merçed del lugar de Campos por aldea desta villa; 396- Merçed de Pliego y Bullas; 397- Preuilejio para que esta villa no pague Portazgos; 398- Unas ordenanzas viejas del rey don Enrrique; 399- Preuilejio de Bullas Pliego y Campos; 400- Confirmaçion general de preuilejios por el rey don Enrrique; 401- Unas sentencias por compromiso entre los terminos de Mula y Zeegin en pergamino; 402- Ordenanzas del rey don enrrique; 403- Un quadernico de la mojonera de Mula y Çieça; 404- Una executoria sobre cosas de la guerra dentro de un pergamino; 405- Un traslado de un preuilejio para que los vezinos de Mula no paguen portazgo en toda Castilla saluo en Murçia y en Toledo; 406- Un padron delos hijosdalgo y pecheros desta villa del año 1409. En rollo ; 407Un padron del año de 1438; 408- Otro del año de 1446; 409- Otro del año de 1495; 410- Otro padron del año 1407; 411- Preuilejio para que lleuen el quinto de las caualgadas los vezinos desta villa9.

Por otro lado, Nicolás Acero y Abad, en su obra Historia de la Muy Noble y Leal Villa de Mula, nos permite aproximarnos a la documentación medieval que estaba depositada en el Archivo Municipal a finales del siglo $\mathrm{XIX}^{10}$. Pedro Martínez Villalta dice que este historiador puso orden en el Archivo Municipal de Mula, sin embargo, no dice si Acero y Abad hizo inventario del fondo municipal ${ }^{11}$.

En dicha obra se hace relación de la documentación más importante recibida por el concejo de Mula durante el periodo bajomedieval, desde la conquista del reino musulmán de Murcia hasta los Reyes Católicos ${ }^{12}$. Ésta es la siguiente: dos privilegios en pergamino, uno de Fernando III y otro del infante don Alfonso, ambos escritos en latín y con data exacta, Jaén 8 de Agosto de 1245, por los que se concede a Mula el Fuero de Córdoba ${ }^{13}$. Un pergamino que contiene el traslado de los dos privilegios rodados anteriores, en romance, y datado el 11 de Diciembre de 1466. Un cuaderno de 75 hojas, con tapas de pergamino y escrito en papel del sello del oficio, que contiene los traslados, autorizados por el escribano Sebastián Zapata y Buitrago, de los documentos anteriores, datado en Mula el 15 de Marzo de $1742^{14}$. Otro privilegio, escrito en romance, en el que Alfonso X concede a Mula las aldeas de Pliego y Bullas con sus castillos, así como todas las rentas y derechos sobre ellas, datado en Murcia el 22 de Julio de $1254^{15}$. Un privilegio rodado de Alfonso X que otorga la merced a Mula del lugar de Campos (actualmente Campos del Río), datado en Alpera el 4 de Julio

$8 \quad$ Ibíd. $C f$. fol. $11 \mathrm{v}$.

$9 \quad$ Ibíd. Cf. fol. 12 r.

10 ACERO Y ABAD, N., Historia de la Muy Noble y Leal Villa de Mula. Tipografía Albadalejo, Murcia, $1886.325 \mathrm{p}$.

11 Ibíd. Cf. ligeras indicaciones sobre la Historia de Mula de Pedro Martínez Villalta que precede a la obra de Acero y Abad. pp. XIII-XIV.

12 Ibíd. Cf. apéndice n ${ }^{\circ}$ III. pp. 250-254.

13 Las transcripciones de ambos documentos están incluidas en la obra de Acero y Abad, tanto en lengua latina, como en romance castellano. $C f$. pp. 166-175.

14 Es posible que en este cuaderno se encontraran los traslados de privilegios y mercedes de reyes posteriores.

15 La transcripción de este privilegio es incluida por Acero y Abad en su Historia de Mula. Cf. pp. 182184. 
de 1295. Privilegio, de Sancho IV cuando era infante, que otorgaba a Mula la posibilidad de traer sesenta casados musulmanes y tener derechos sobre ellos ${ }^{16}$ Confirmación de Sancho IV a Mula de los privilegios otorgados por Fernando III y Alfonso X, datado en Almagro el 22 de Abril de 1283. Merced de este mismo rey concediendo a Mula el "séptimo de las cabalgadas", datada en Burgos el 22 de Marzo de 1285. Confirmación de Fernando IV de todos los privilegios anteriores: el Fuero de Córdoba, la posesión de las aldeas de Pliego, Bullas y Campos, así como el privilegio que Alfonso X dio a Mula eximiéndola del pago de peaje y portazgo en toda Castilla, excepto en Sevilla, Toledo y Murcia, el privilegio para que la villa pudiera tener mercado todos los viernes, el privilegio para que los vecinos de Mula no pagasen portazgo ni almojarifazgo de lo que vendiesen en Murcia, y por último, el privilegio de no pagar almojarifazgo de lo que los vecinos de la villa ganasen en la gue$\mathrm{rra}^{17}$. Una confirmación de Fernando IV de la merced de Sancho IV a Mula para traer a la villa sesenta parejas de musulmanes, datada en Cuellar el 3 de Marzo de $1296^{18}$. Segunda confirmación de Fernando IV de los privilegios de la villa, datada en Ciudad Rodrigo el 3 de Julio de 1298. Una merced de Alfonso XI otorgando a Mula el uso de las yerbas, prados, montes y franqueza de almojarifazgo, datada en Córdoba el 30 de Septiembre de 1317. Un cuadernillo, en pergamino, en el que Alfonso XI accede a las peticiones hechas por las ciudades y villas de sus reinos en las Cortes de Valladolid, datado el 12 de Diciembre de 1325. Una confirmación, del mismo rey, del privilegio de Alfonso X que eximía a los vecinos de Mula del pago del almojarifazgo en Murcia, datada en León el 10 de Marzo de 1335. Una merced de Alfonso XI otorgando a Mula el uso de yerbas, montes, prados, caza y grano, y una confirmación del mismo rey sobre la posesión de Pliego, Bullas y Campos; ambos documentos con la misma data tópica y cronológica que el anterior. Otra confirmación de Pedro I de los cuatro privilegios que Alfonso XI dio a Mula, datado en Valladolid el 10 de Diciembre de 1351: el primero eximía del pago de portazgo y almojarifazgo, el segundo concedía el "séptimo de las cabalgadas" y aventuras, el tercero el dominio de la dehesa de Cagitán y el cuarto el uso de yerbas y montes. ${ }^{19}$ Un privilegio de confirmación de Pedro I, con la misma data tópica y cronológica que la anterior, que ratifica la merced de Fernando IV otorgada a Mula sobre la renta del portazgo y tahurería, y otorgamiento de la merced de poder arrendar y vender montes y yerbas a beneficio del concejo ${ }^{20}$. Otra confirmación del conde de Carrión, don Juan Sánchez Manuel, de las mercedes y los capítulos que el concejo

16 Ibíd. Cf. p. 188, nota 2.

17 Acero y Abad no nos dice la data de estas confirmaciones, ni siquiera, si estaban insertas en un mismo documento o eran independientes. Ibíd. Cf. p. 250.

18 Antonio Sánchez Maurandi considera que, en la confirmación de esta merced, otorgada en nombre del rey por su madre, estaban incluidas las confirmaciones anteriores, además dice que son cien parejas de musulmanes las que podían llegar a la villa. SÁNCHEZ MAURANDI, A., Historia de Mula, Tipografía San Francisco, Murcia, 1955, p. 36.

19 El privilegio de la dehesa de Cagitán a Mula lo otorgó Alfonso X. El original de este documento desapareció, del archivo de la villa, durante el asedio a Mula por las tropas de Pedro III el Grande de Aragón, las cuales quemaron parte de la villa y el archivo. Acero y Abad conoce esta información a través de la confirmación de Pedro I, en la cual se incluía inserta la confirmación de Alfonso XI a Mula de la posesión de la misma dehesa, y en la que se relataba el episodio del asedio a la villa y la destrucción de parte de su archivo. ACERO Y ABAD, N., $C f$. p. 195.

20 La merced de Fernando IV fue otorgada en Burgos el 7 de Junio de 1298. Ibíd. Cf. pp. 196 y 251. 
de Mula le presentó, datado en Murcia el 27 de Mayo de $1369^{21}$. Confirmación de Enrique II de los capítulos contenidos en el documento anterior, otorgado en las Cortes de Toro el 10 de Septiembre de $1371^{22}$. Confirmación de Juan I de los capítulos anteriormente citados, datado en Burgos el 10 de Noviembre de 1379. Un privilegio de confirmación de Enrique III, otorgado en las Cortes de Madrid el 15 de Diciembre de 1393, ratificando uno anterior de Juan I, en el que eximía a Mula del pago de la moneda "forera" en un total de ochenta vecinos $^{23}$. Otro privilegio de confirmación por el que Enrique III reafirma los privilegios, usos y costumbres de la villa de Mula, otorgado, también, en las Cortes de Valladolid el 15 de Diciembre de $1393^{24}$. Otro privilegio de confirmación de Juan II por el que ratifica a la villa el "séptimo de las cabalgadas", datado en Valladolid el 16 de agosto de $1420^{25}$. Un privilegio de confirmación de todos los privilegios de la villa por Juan $\mathrm{II}^{26}$. Privilegio de confirmación de todos los privilegios otorgados a la villa por Enrique IV, datado en Palencia el 15 de Enero de 1456. Una Real Cédula de los Reyes Católicos por la que confirmaban todos los privilegios, mercedes, libertades y franquicias a la villa de Mula, datada en $1480^{27}$. Y, finalmente, un padrón que fue ordenado hacer por los Reyes Católicos en 1495, escrito en papel y conocido como el Padrón de los Jueces, debido a que fue realizado por los jueces don Alonso del Castillo y don Juan Barrionuevo ${ }^{28}$.

A día de hoy, de toda esta documentación referida, la gran mayoría de ella no se encuentra en el Archivo Municipal, ni en forma original ni en traslado. Los documentos en pergamino conservados son: el privilegio rodado de Fernando III por el que otorga a Mula el Fuero de Córdoba, escrito en latín ${ }^{29}$; otro privilegio rodado por el que Alfonso X otorga el lugar de Campos a la villa de Mula $^{30}$; un cuadernillo de pergamino “in quarto” por el que Alfonso XI accede a las peticiones de las ciudades, villas y lugares de sus reinos, dado en las Cortes de Valladolid de $1325^{31}$; una carta de privilegio de confirmación de Enrique III sobre la exención del pago de la

21 Acero y Abad hace relación de los capítulos presentados por el concejo de Mula a don Juan Sánchez Manuel, conde de Carrión. Ibíd. Cf. pp. 198-199.

22 Acero y Abad afirma que en este documento se añaden otras concesiones a los vecinos de Mula, como la licencia para entrar en tierras granadinas, y otras. Ibíd. $C f$. p. 200.

23 El privilegio de Juan I sobre la exención del pago de la moneda "forera", inserto en el privilegio de confirmación de Enrique III, estaba datado en Cuellar el 4 de Agosto de 1389. Cf. A. M. Mula. Carpeta de privilegios, doc. $\mathrm{n}^{\circ} 1$.

24 Este documento de confirmación, aunque tenía la misma data era independiente, como he podido comprobar al leer la confirmación sobre la moneda "forera".

25 ACERO Y ABAD, N., Cf. p. 197.

26 Acero y Abad no nos facilita la data de este privilegio de confirmación. ACERO Y ABAD, N., $C f$. apéndice III, p. 253.

27 Acero y Abad sólo nos dice el año. Sin embargo, Sánchez Maurandi nos ofrece más datos cronológicos: Medina del Campo, 31 de Octubre de 1480. (A.G.S. Registro General del Sello. Octubre 1480. fol. 2). Cf. SÁNCHEZ MAURANDI, A., Historia de Mula, 1955, p. 45.

28 ACERO Y ABAD, N., Cf. p. 202.

29 1245, Agosto, 8. Jaén. A.M.Mula. Carpeta de privilegios, doc. no 5. Privilegio rodado. Original en pergamino. Este documento fue adquirido por el Ayuntamiento de Mula a principios de los años ochenta del siglo pasado.

30 1257, Julio, 4. Alpera. A.M.Mula. Carpeta de privilegios, doc. $n^{\circ}$ 6. Privilegio rodado. Original en pergamino

31 1325, Diciembre, 12. Valladolid. A.M.Mula. Otros documentos 2. Cuadernillo original en pergamino. 
moneda "forera" 32 . Una cosa curiosa de esta carta de privilegio es que, actualmente, pende de ella un sello de plomo cuya materia sustentante no es la original, además, aún se pueden observar en el interior del sello restos de los hilos originales (hilo de seda rojo, amarillo y verde), por lo que no se puede asegurar que éste pertenezca a este privilegio. Por otro lado, actualmente, se hallan en el archivo documentos que no aparecen en los inventarios del siglo XVII, ni tampoco son referidos por Acero y Abad. Éstos debieron llegar al Archivo en algún momento del siglo $\mathrm{XX}^{33}$; además no tienen relación, a excepción de un documento, con el concejo de Mula ni con sus vecinos. Por orden cronológico, estos documentos son los siguientes: una provisión de Juan I en la que confirma a los herederos de Pedro López de Ayala en la posesión de los lugares de Albudeite y Campos, datada en Valladolid el 18 de Febrero de $138 \mathrm{O}^{34}$. Una carta de avenencia en la que el maestre de Santiago, don Lorenzo Suárez de Figueroa, confirma al concejo de Cehegín un acuerdo sobre términos establecido con Caravaca, datada en Caravaca el 16 de Septiembre de $1390^{35}$. Otra carta de avenencia entre el concejo de Mula y Aldonza Fernández de Ayala, señora de Albudeite, en la que ésta se compromete a pagar al concejo de Mula cinco florines de oro al año para que sus vasallos puedan entrar, y obtener recursos, dentro de los términos de la villa de Mula, datada en la villa de Hita, a martes 8 de Marzo de 1401. A continuación de este documento, y dentro de la misma materia escriptoria, se manuscribe la ratificación de la carta de avenencia por el concejo de Mula, datada en Mula el 24 de Junio de $140{ }^{36}$. Y por último, una carta de privilegio del maestre de Santiago, don Enrique infante de Aragón, en la que confirma todos los privilegios, fueros y mercedes, otorgados por maestres anteriores, a la villa de Cehegín, datada en Uclés el 8 de Noviembre de $1440^{37}$.

Por otro lado, aún se conservan, en el Archivo Municipal, varios padrones de hidalgos y pecheros escritos en papel y muy deteriorados. Encuadernados conjuntamente en pergamino y con sus traslados en 1759 , se encuentran los padrones de $1407^{38}$, de $1438^{39}$ y $1446^{40}$. Junto a éstos se encuentra el último padrón medieval, conocido como Padrón de los Jueces, realizado en $1495^{41}$.

De toda la documentación, hoy en pergamino conservada en el Archivo Municipal de Mula, se hace catálogo-inventario desde la óptica diplomática, paleográfica, sigilográfica y codicológica, objeto del presente trabajo.

32 1393, Diciembre, 15. Cortes de Madrid. A.M.Mula. Carpeta de privilegios, doc. $\mathrm{n}^{\circ} 1$. Carta de privilegio. Original en pergamino.

33 Solamente se conoce la fecha de entrada de uno de estos documentos al archivo.

34 1380, Febrero, 18. Valladolid. A.M.Mula. Carpeta de privilegios, doc. $\mathrm{n}^{\mathrm{o}} 2$. Provisión. Original en pergamino. Este documento fue adquirido por el Ayuntamiento de Mula en 1999, y es al que me refería en la nota anterior.

35 1390, Septiembre, 16. Caravaca. A.M.Mula. Carpeta de privilegios, doc. $\mathrm{n}^{\circ}$ 4. Carta de avenencia. Original en pergamino. En este documento se inserta otra carta de avenencia entre las mismas villas, datada el 11 de Noviembre de 1365 .

36 1401, Marzo, 8. Marte, villa de Hita. A.M.Mula. Carpeta de privilegios, doc. n³; 1401, Junio, 24. Mula. A.M.Mula. Carpeta de privilegios, doc. $n^{\circ} 3$. Carta de avenencia. Original en pergamino.

37 1440, Noviembre, 8. Uclés. A.M.Mula. Carpeta de privilegios II. Carta de privilegio. Original en pergamino. En este documento se insertan los privilegios otorgados por maestres anteriores.

38 1407, Mayo, 24. Mula. A.M.Mula. Fondo Municipal, leg. 340. Papel, 12 hojas numeradas.

39 1438. Mula. A.M.Mula. Fondo Municipal, leg. 340. Papel, 7 hojas numeradas.

40 1446. Mula. A.M.Mula. Fondo Municipal, leg. 340. Papel, 23 hojas numeradas.

41 1495, Septiembre, 3. Mula. A.M.Mula. Fondo Municipal, leg. 340. Papel, 6 hojas numeradas. 


\begin{abstract}
1245, Agosto, 8. Jaén.
Fernando III de Castilla concede el Fuero de Córdoba a la villa de Mula, eximiendo a ésta del pago de peaje y portazgo en todo el reino, excepto en Murcia y Toledo.
\end{abstract}

A.- A.M.Mula. Carpeta de Privilegios, documento $\mathrm{n}^{\circ}$ 5. Privilegio Rodado. Pergamino de corte irregular (404 x $418 \mathrm{~mm}$ ). Buen estado de conservación, pero presenta agujeros producidos por el paso del tiempo o por insectos. Tinta ocre. Escritura gótica cursiva corriente tipificada llamada de "privilegios". Lengua latina. Presenta plica de $64 \mathrm{~mm}$ con tres óculos en posición central de donde pendería sello de plomo. Inicia el documento a modo de invocación monogramática un crismón encerrado en doble círculo de $75 \mathrm{~mm}$. Presenta rueda de $119 \mathrm{~mm}$ en posición central; la rueda y el crismón están realizados en tinta ocre y monocromos al igual que el texto; ambos elementos contienen anotaciones en escritura humanística en tinta negra. A ambos lados de la rueda se sitúan listas de confirmantes. En la parte inferior izquierda aparecen tres líneas, escritas posteriormente, en letra humanística y tinta negra. Letra de módulo grande al comienzo del documento: letra "T", y en el centro del primer renglón: FERNANDUS. Escriturado el pergamino en su lado de carne; en su lado de pelo, aparecen anotaciones en escritura humanística.

EDIT:

- ACERO Y ABAD, N., Historia de la Muy Noble e Leal Villa de Mula, Tipografía Albadalejo, Murcia, 1886, pp. 166-168.

- SÁNCHEZ MAURANDI, A., Historia de Mula, Tipografía San Francisco, Murcia, 1955, pp. 33-34.

- TORRES FONTES, J. (ed.), Fueros y privilegios de Alfonso X el Sabio al Reino de Murcia. Colección de Documentos para la Historia del Reino de Murcia, tomo III, Academia Alfonso X el Sabio, Murcia, 1973, doc. VII, pp. 8-9.

- ORTEGA LORCA, J., Edición crítica de la descripción Chorográfica del sitio que ocupa la provincia regular de Carthagena de mi P. S. Francisco del R. P. F. Pablo Manuel Ortega, Academia Alfonso X el Sabio, Murcia, 1994, pp. 346-348.

II

\title{
1257, Julio, 4. Alpera.
}

Alfonso X otorga al concejo de Mula el lugar de Campos (Campos del Río, Murcia).

A.- A.M.Mula. Carpeta de Privilegios, documento $n^{\circ}$ 6. Privilegio rodado. Pergamino (540 x $402 \mathrm{~mm}$ ). Estado de conservación regular, presentando desgaste de la tinta en los márgenes del documento, manchas de humedad y un agujero debajo de la rueda. Tinta ocre. Escritura gótica cursiva corriente tipificada denominada de "privilegios". Lengua romance castellana. Presenta plica de $60 \mathrm{~mm}$ con tres óculos en posición central de donde pendería sello de plomo. Inicia el documento a modo de invocación monogramática un crismón encerrado en doble círculo de $63 \mathrm{~mm}$; presenta una cruz en la parte superior del anagrama, dentro del bucle de "p", propio de la cancillería alfonsí. Presenta rueda de $168 \mathrm{~mm}$ inacabada en posición central, en la que no 
aparece, en el círculo central, simbología alguna. A ambos lados de la rueda se sitúan listas de confirmantes. Utilización de letra de módulo grande en los nombres del rey y la reina dentro de una cuadrícula. Escriturado el pergamino en su lado de carne; en su lado de pelo, aparecen anotaciones en escritura humanística. Presenta anotaciones de 1436 a izquierda y derecha en el interior de la plica: “... si estan dello en posesion..." a la izquierda; "ha CLXXIX annos que se fiso este priuillejo" a la derecha. En el exterior de la plica, a la derecha, en el mismo tipo de letra aparece: "preuillejo del sennorio de Campos".

CIT:

- ACERO Y ABAD, N., Historia de la Muy Noble e Leal Villa de Mula, Tipografía Albadalejo, Murcia, 1886, p. 186.

- SÁNCHEZ MAURANDI, A., Historia de Mula, Tipografía San Francisco, Murcia, 1955, p. 34.

- ORTEGA LORCA, J., Edición crítica de la descripción Chorográfica del sitio que ocupa la provincia regular de Carthagena de mi P. S. Francisco del R. P. F. Pablo Manuel Ortega, Academia Alfonso X el Sabio, Murcia, 1994, p. 245.

III

1380, Febrero, 18. Valladolid.

Juan I de Castilla confirma a los herederos de Pedro López de Ayala, Sancho y Aldonza, la tenencia y posesión del lugar de Albudeite, la fortaleza de Albudeite y el lugar de Campos en el pleito mantenido con Constanza de Villena.

A.- A.M.Mula. Carpeta de privilegios, documento $n^{\circ}$ 2. Provisión. Pergamino (520 x $428 \mathrm{~mm}$ ). Buen estado de conservación, aunque presenta pequeñas roturas por donde había estado doblado con anterioridad, pero no entorpecen la lectura. Tinta ocre. Escritura gótica cursiva corriente tipificada llamada de "privilegios". Lengua romance castellana. Presenta plica de $87 \mathrm{~mm}$ con tres óculos en posición central y con restos de hilo de seda a colores, del que pendería sello de cera. Escriturado el pergamino en su lado de carne; en su lado de pelo, aparecen anotaciones en escritura humanística. Raspado de posible corrección coetánea a la escrituración del documento sobre el que se ha escrito en el renglón 39 "quanto para”. En el renglón 52 aparece resalte de tinta ocre más oscura contemporánea a la época de escrituración "Mille e dozientos"; ídem en el renglón 55.

\section{IV}

1390, Septiembre, 16. Caravaca.

El maestre de Santiago Don Lorenzo Suárez de Figueroa confirma al concejo de Cehegín el acuerdo establecido con Caravaca sobre términos. Inserta carta de avenencia entre el concejo de Cehegín y Caravaca sobre términos de fecha 11 de Noviembre de 1365.

A.- A.M.Mula. Carpeta de Privilegios, documento $n^{\circ} 4$. Carta de avenencia. Pergamino de corte irregular $(280$ x $450 \mathrm{~mm})$. Estado de conservación regular, presentando agujeros 
por donde estaba plegado que entorpecen la lectura; manchas de humedad en los márgenes y encima de la plica. Tinta ocre. Escritura gótica cursiva corriente tipificada llamada "cortesana". Lengua romance castellana. Presenta plica de $50 \mathrm{~mm}$ con tres óculos en posición central de donde pendería sello de cera. Escriturado el pergamino en su lado de carne; en su lado de pelo, aparecen anotaciones en escritura humanística. A la altura del renglón 13 aparece signo cruciforme en el margen izquierdo

\section{EDIT:}

- TORRES FONTES, J., Documentos para la historia medieval de Cehegín, Academia Alfonso X el Sabio, Murcia, 1982, pp. 153-157, doc. 18.

\section{$\mathbf{V}$}

1393, Diciembre, 15. Cortes de Madrid.

Enrique III de Castilla confirma a la villa de Mula un privilegio eximiéndole de pagar moneda forera, en número de 80 vecinos, elegidos por el concejo. Inserta el privilegio original de Juan I, dado en Cuellar el 4 de agosto de 1389.

A.- A.M.Mula. Carpeta de privilegios, documento $n^{\circ} 1$. Carta de privilegio. Pergamino (255 x $603 \mathrm{~mm}$ ). Buen estado de conservación aunque un poco deteriorado en aquellas partes por donde estaba plegado. Tinta ocre. Escritura gótica cursiva corriente tipificada, llamada de "privilegios". Lengua romance castellana. Presenta plica de $50 \mathrm{~mm}$ con tres óculos en posición central de la que pende sello redondo de plomo de $53 \mathrm{~mm}$ cuya materia sustentante no es original por conservar restos de hilo de seda rojo, amarillo y verde. Falta la "S" de módulo grande al inicio del documento. La prolongación de los astiles de las letras de la $1^{\mathrm{a}}$ línea invalida el margen superior del documento. Escriturado el pergamino en su lado de carne; en su lado de pelo, aparecen anotaciones en escritura humanística. Raspados de posibles correcciones coetáneas a la escrituración del documento sobre los que se han escrito en el renglón 16 "conceio de la dicha Villa de mula”; renglón 17 ídem; renglón 19 “conceio”; renglón 21 ídem.

CIT:

- ACERO Y ABAD, N., Historia de la Muy Noble e Leal Villa de Mula, Tipografía Albadalejo, Murcia, 1886, p. 197.

- SÁNCHEZ MAURANDI, A., Historia de Mula, Tipografía San Francisco, Murcia, 1955 , p. 40.

- VEAS ARTESEROS, F., Itinerario de Enrique III, Murcia, 2003, p. 317, regesta ${ }^{\circ}$ 606.

\section{VI}

1401, Marzo, 8. Martes, villa de Hita.

Aldonza Fernández, de Ayala, señora de Albudeite, se compromete a pagar anualmente 5 florines de oro al concejo de Mula para que sus vasallos puedan utilizar tierras y otros provechos del término de Mula. 
A.- A.M.Mula. Carpeta de privilegios, documento n ${ }^{\circ}$ 3. Carta de avenencia. Pergamino (490 x $375 \mathrm{~mm}$ ). Buen estado de conservación aunque presenta rotura por donde estaba plegado que no entorpece la lectura; en los márgenes izquierdo y derecho presenta cierta dificultad de lectura por pérdida de la tinta. Aparece reescriptos posteriores supliendo esta lagunas en el margen derecho. Tinta ocre. Escritura gótica cursiva corriente tipificada llamada "precortesana". Lengua romance castellana. Inicia el documento una " $\mathrm{E}$ " de módulo grande en tinta ocre. Escriturado el pergamino en su lado de carne; en su lado de pelo, aparecen anotaciones en escritura humanística. Tras dos agujeros en forma de rombo se escritura el documento $\mathrm{n}^{\circ} 7$.

\section{VII}

1401, Junio, 24. Mula.

El concejo de Mula confirma y ratifica la avenencia hecha por Pero González de Leyva, procurador del concejo, con Aldonza Fernández de Ayala señora de Albudeite.

A.- A.M.Mula. Carpeta de privilegios, documento n ${ }^{\circ} 3$. Carta de confirmación. Pergamino (490 x 375). Regular estado de conservación. Tinta ocre. Escritura gótica cursiva corriente tipificada llamada "precortesana". Lengua romance castellana. Plica de $30 \mathrm{~mm}$ con tres óculos en posición central, con restos de hilos de cáñamo de color marrón oscuro de donde pendería sello de cera del concejo de Mula. Escriturado el pergamino en su lado de carne; en su lado de pelo, aparecen anotaciones en escritura humanística. Este documento sigue a continuación del documento $\mathrm{n}^{\circ} 6$ en la misma pieza escriptoria.

CIT:

- SÁNCHEZ MAURANDI, A., Historia de Mula, Tipografía San Francisco, Murcia, 1955 , p. 41

- VEAS ARTESEROS, Fco., "El siglo XV” en Historia de Albudeite, Murcia, 2000, pp. 57-77. Cf. p. 60, nota 33 .

- LISÓN HERNÁNDEZ, L., "Campos desde la Edad Media al siglo XVI” en Historia de Campos del Río, Murcia, 1997, pp. 33-65. Cf. p. 45, nota 24.

\section{VIII}

1440, Noviembre, 8. Uclés.

Don Enrique Infante de Aragón, maestre de la Orden de Santiago, confirma los privilegios, fueros y mercedes dados por los maestres anteriores a la villa de Cehegín, los cuales se insertan: 1307, Mayo, 15. Zamora; 1315, Abril, 2. Montiel; 1317, Junio, 28. Córdoba; 1344, Diciembre, 17. Corral de Almaguer; 1344, Diciembre, 18. Corral de Almaguer; 1344, Diciembre, 28. Corral de Almaguer; 1352, Enero, 8. Montiel; 1371, Agosto, 1. Ocaña; 1403, Marzo, 25. Mérida; 1413, Octubre, 13. Medina del Campo; 1416, Agosto, 20. Valladolid.

A.- A.M.Mula. Carpeta de privilegios II. Carta de privilegio. Pergamino (780 x 600 $\mathrm{mm}$ ). Estado de conservación malo, presentando rotura del margen superior izquierdo y 
agujeros repartidos por todo el documento, además de una gran mancha en la zona central y por todo el margen derecho. Tinta ocre. Escritura gótica cursiva corriente tipificada denominada de "privilegios". Lengua romance castellana. Presenta plica de $68 \mathrm{~mm}$ de donde penderían sellos de cera del maestre de la orden y del cabildo. Falta la letra "D" de módulo grande al inicio del documento. La prolongación de los astiles de las letras de la $1^{\text {a }}$ línea invalida el margen superior del documento. Escriturado el pergamino en su lado de carne.

\section{EDIT:}

- TORRES FONTES, J., Documentos para la Historia Medieval de Cehegín, Academia Alfonso X el Sabio, Murcia, 1982, pp. 177-180, doc 23.

\section{IX}

1325, diciembre, 12. Valladolid.

Alfonso XI otorga y responde a lo pedido en cortes por las ciudades, villas y lugares de sus reinos.

A.- A.M.Mula. Otros documentos 2. Cuaderno de cortes. Cuadernillo de pergamino, septenion, de factura irregular “in quarto", de 238/245 x 158/162 mm. No cumple la regla de Gregory ${ }^{42 *}$. Cosido a dos hiladas con tira de pergamino anudada. Presenta incisión sobre el orificio inferior del cosido de donde pendería sello de cera del rey. Buen estado de conservación. Tinta ocre. Escritura gótica cursiva corriente tipificada denominada de "privilegios", con rasgos de la también denominada de "albalaes". Lengua romance castellana. Presenta numeración arábiga en margen superior derecho, excepto en la última página. Aparecen anotaciones marginales en la página 4 en el margen izquierdo; en la página 5 manícula en el margen izquierdo; en la página 10 signo cruciforme en el margen izquierdo.

CIT:

- ACERO Y ABAD, N., Historia de la Muy Noble e Leal Villa de Mula, Tipografía Albadalejo, Murcia, 1886, p. 197.

$42 *$ Un pergamino tiene un lado de pelo y otro de carne; para que se cumpla la regla de Gregory hay que colocar, sucesivamente, dos bifolios yuxtapuestos por la misma cara, partiendo del verso del primero del cuaderno. RUIZ GARCÍA, E., Introducción a la Codicología, Fundación Germán Sánchez Ruipérez, Madrid, 2002 (2ª ed.). $C f$. pp. $147-148$. 